DOI: https://doi.org/10.17979/rgf.2009.10.0.3923

\title{
Centralidade e prominencia nas relacións gramaticais
}

\author{
Francisco A. Cidrás Escáneo \\ Universidade de Santiago de Compostela
}

\begin{abstract}
Resumo:
O traballo comeza cunha breve caracterización da oposición centro-periferia nos sucesivos niveis de abstracción identificables no proceso de construción de enunciados: do acto de fala concreto individual ao plano abstracto esquemático da sintaxe, pasando polo léxico. A partir de aí, o estudo céntrase no plano sintáctico das relacións gramaticais, presentadas nunha xerarquía de centralidade que evoca e dalgún xeito codifica a prominencia conceptual dos elementos que integran a imaxe mental que o falante ten da súa propia mensaxe. Préstase especial atención á zona intermedia desa xerarquía, onde atopamos os complementos de Obxecto non-Directo (OI e OP). Estes, segundo se propón, conflúen nesa zona respondendo en boa medida a estratexias dinámicas contrapostas (de promoción e marxinalización), que se caracterizan sobre a base dos datos do galego.
\end{abstract}

\section{Palabras chave:}

Centro, periferia, funcións, Obxecto Indirecto, Obxecto Directo, galego.

\begin{abstract}
:
This paper starts with a brief overview of the core-periphery opposition through the successive levels of abstraction which can be identified in the process of utterance construction: from the actual, individual speech act up to the abstract, schematic level of syntax, going through the lexicon. From this point of departure, the study focuses on the syntactical level of grammatical relations, arranged according to a centrality hierarchy which evokes and somehow encodes the conceptual prominence of the entities making up the speaker's mental image of his/her own message. Special attention is paid to the intermediate zone of this hierarchy, where non-Direct Object complements $(I O, P O)$ are found. According to what is proposed here, these relations converge in such a region as a result of opposite dynamics (promotion and demotion strategies), which are described on the basis of data from Galician.
\end{abstract}

\section{Key words:}

Core, periphery, grammatical relations, Indirect Object, Prepositional Object, Galician.

\section{Centro e periferia no sistema lingüístico}

É ben coñecida a pertinencia de diferenciar na descrición do sistema lingüístico entre elementos centrais e elementos periféricos. Seguramente se trata dunha constante epistemolóxica común a calquera ámbito do coñecemento, pero no campo da lingüística moderna é unha dualidade crucial cando menos desde os traballos do 
Círculo de Praga — nomeadamente coa referencia inexcusable das achegas incluídas en TLP2 (1966). Esta propiedade maniféstase en todos niveis da análise lingüística e remite á concepción do sistema das linguas como unha entidade flexible, dinámica e adaptativa, de consistencia fluída e con diferentes densidades de estruturación, e non como algo ríxido, estático e uniforme en todos os seus puntos. Neste senso, o centro correspóndese coas zonas máis densamente estruturadas do sistema, en que atopamos os elementos máis produtivos, regulares e máis codificados, mentres que na periferia (as marxes do sistema) se localizan os elementos menos produtivos e por tanto máis escasamente codificados, estruturados dunha maneira máis laxa, o cal non quere dicir en absoluto que carezan de estrutura, é dicir, dunha forza de cohesión, igual que, en termos físicos, os corpos fluídos tamén non carecen dela. Esta diferenciación de zonas con distinta densidade estrutural é produto dun principio xeral da organización dos sistemas lingüísticos que, amentando a Du Bois (1985: 363), podemos enunciar coa seguinte máxima: "Grammars code best what speakers do most" — mesmamente porque os falantes son os indutores desa codificación gramatical e axústana ás súas necesidades operativas, procurando a óptima eficiencia do sistema coa densidade normativa estritamente necesaria para acadar aquela.

Xa que logo, tamén no estudo das unidades sintácticas, e nomeadamente no nivel oracional, é habitual distinguir entre elementos centrais e periféricos. Porén, máis alá da relevancia epistémica da distinción, acostuman quedar pouco perfilados en cada caso os límites entre ambas as zonas. Adoita alegarse esta 'imprecisión' como evidencia do carácter non-discreto da oposición e, desde logo, en parte é responsabilidade súa. Mais ten moito que ver tamén con outras características desa división topográfica:

a) a existencia de fluxos de transferencias entre centro e periferia en ambos os sentidos, tanto de integración de elementos periféricos cara ao núcleo de sistema (no sentido de Vachek 1966), como inversamente de marxinación de elementos centrais cara á periferia do sistema ${ }^{1}$;

b) a reprodución desa oposición centro-periferia nos distintos niveis de abstracción identificables no proceso de construción de predicacións. En cada un deles a dualidade maniféstase de maneiras que gardan fortes similitudes, pero que en realidade son sensiblemente distintas, o que propicia identificacións enganosas.

Verbo dos fluxos de transferencias entre centro e periferia, nesta contribución caracterizarei precisamente as funcións OP e OI como mecanismos de integración de constituíntes marxinais e de marxinación de constituíntes centrais, respectivamente,

1 Pénsese, como exemplo de integración, na conversión do resoprido, xesto sonoro que manifesta alivio, cansazo, fastío etc., en interxección uf, buf, e a seguir a destas en formas léxicas plenas como ufar, bufar. Simetricamente exemplifican procesos de marxinación as interxectivacións de formas léxicas plenas, sobre todo aquelas en que se produce unha transfiguración fónica que as converte virtualmente en interxeccións primarias: ho, benia, canté. 
no ámbito da oración (véxase infra, secc. 3). Porén, querería reparar agora na segunda das devanditas propiedades (b), máis esquecida que a primeira pero se cadra máis relevante para a exploración dos 'imprecisos' confíns entre centro e periferia. As aludidas identificacións enganosas dan lugar a certa dose de imprecisión ilusoria, en tanto que nos levan a interpretar como un problema de vaguidade (isto é, de imposibilidade intrínseca de adscrición dun elemento a un sistema de categorías proposto, ao compartir atipicamente características prototípicas de varias delas) cousas que realmente son produto de mesturarmos ou non distinguirmos niveis - $\mathrm{O}$ cal non exclúe que si poida haber vaguidade no interior de cada un deles.

O proceso de construción de predicacións opera en diferentes niveis de abstracción. No plano máis rasante de cada acto de fala individual, o emisor comeza por construír no seu cerebro unha imaxe mental (conceptualización prelingüística) en que retén selectivamente un número variable de elementos recuperados da memoria episódica en que almacena información sobre a realidade evocada que pretende comunicar. $\mathrm{O}$ número e características dos elementos integrantes desa imaxe mental son certamente imprevisibles e non están predefinidos. Para referirse, por exemplo, a un evento concreto como, poñamos, unha comedela, pódelle parecer pertinente referirse aos individuos que inxiren alimentos e aos alimentos inxeridos, ou tamén prescindir dalgunha desas entidades (mesmo das dúas) e referirse ao lugar e ao tempo en que se desenvolve o evento, ou integrar as catro (ou outras máis) na imaxe, cada unha delas con diferente grao de prominencia no cadro mental, imposible de prever a priori etc. As conceptualizacións dos actos de fala individuais, entidades prelingüísticas ao cabo, abranguen por tanto un número indeterminado de elementos, que só poderían identificarse como nucleares ou periféricos coñecendo a súa prominencia ou peso especifico na imaxe mental do falante, e de acordo cunha gradación que ten a forma dun continuo imperceptible, pero tamén intransferible a outras persoas.

Dado que as conceptualizacións correspondentes a cada acto de fala individual son, pola súa propia natureza, persoais e intransferibles, as linguas (como sistemas de transferencia de comunicación entre individuos) posúen un almacén de conceptualizacións predefinidas e compartidas polo conxunto dos seus usuarios, que constitúen o seu acervo lexical ou lexicón (Givón 1998: 43-44). Cada entrada léxica evoca a conceptualización dun tipo de entidade ou de evento socialmente recoñecido (por recorrente ou relativamente frecuente nesa sociedade), que os membros da comunidade convencionalmente identifican mediante esa etiqueta. O lexicón conceptual integra o que en psicoloxía cognitiva se coñece como memoria semántica, distinta da memoria episódica (Atkinson / Shiffrin 1968). O plano léxico supón por tanto un importante nivel de abstracción sobre o plano dos actos de fala individuais: fronte ao carácter infinito e asistemático destes, o repertorio lexical dos falantes está integrado por un número aberto pero finito de elementos estruturados na mente dos falantes mediante complexas redes de nodos e conexións, seguramente ás veces de carácter difuso e densidade variable. Fronte ao que ocorre coas imaxes mentais individuais, a 
conceptualización socialmente asumida que encerra cada ítem lexical está integrada por un número de participantes limitado e predefinido (no caso anterior da inxesta de alimentos, teriamos o ítem comer, que integra dous elementos na escena mental), de xeito que a predicación construída sobre esa base conterá de entrada uns determinados constituíntes seleccionados polo predicado (dous no caso de comer), que conformarán a predicación nuclear. Esta poderase acrecentar ademais cun número variable doutros elementos con información puntualmente relevante (aínda que no lexicón non se lle presupón esa prominencia) que constitúen a periferia da predicación.

Así pois, a oposición centro-periferia, que no nivel da conceptualización individual se resolvía nun continuo de elementos da máxima á mínima prominencia, no plano lexical resólvese nunha coñecida oposición de dúas categorías relativamente ben caracterizable: os actantes ou argumentos fronte aos circunstantes ou adxuntos. Manifestación da relevancia metodolóxica desa distinción categorial é o distinto comportamento que uns e outros elementos reciben na configuración sintáctica da oración, pero en realidade isto sitúanos xa no seguinte nivel de abstracción, ao que nos referiremos de seguido. Sen saírmos do plano lexical, o certo é que non existen criterios formais que permitan delimitar con claridade os actantes dos circunstantes (Báez 1988: 79ss, García-Miguel 1995a: 23-31, Moure 1996: 203-207). Porén, na miña opinión, isto non quere dicir que esteamos perante un continuum gradativo: a acumulación de probas propostas non deseña unha escala cuns elementos máis prototipicamente argumentais e outros menos (segundo o número variable de probas que cumpran), senón que evidencia a ineficacia de calquera proba formal aplicada a unha oposición que de seu é conceptual (trataríase de saber qué entidades entran na conceptualización etiquetada e cales non), aínda que esta sexa socialmente compartida. Neste senso resultan significativas constatacións empíricas como a seguinte:

La confrontation systématique de deux dictionnaires ne nous a donné que très peu de différences, ce qui nous porte a croire que les difficultés suscitées par la distinction nucléaire/périphérique se situent beaucoup plus dans la recherche de propriétés formelles distinctives que dans l'établissement même de la distinction. Le problème est d'arriver à formaliser l'intuition (Willems 1981: 37).

A identificación de manifestacións formais da distinción entre centro e periferia só se pode facer, pola propia natureza do procurado, situándonos no nivel das construcións sintácticas. Estas construcións supoñen a redución das numerosísimas unidades lexicais dunha lingua (de carácter atómico e substantivo) a un reducido repertorio de unidades complexas e esquemáticas — no sentido habitual de todos estes termos en gramática cognitiva (Croft / Cruse: 2004). Situámonos tamén así na zona máis densamente estruturada do sistema lingüístico. As construcións son configuracións sintácticas, esquemas abertos e razoablemente ben definidos, identificables mediante numerosas marcas formais. Isto é así porque en realidade non teñen existencia á marxe desas marcas: os esquemas sintácticos son instrumentos ao servizo da capacidade 
ilimitada de codificar, no plano da expresión, contidos, pero eles (como ocorre con toda a aparataxe instrumental) si teñen carácter limitado e discreto. A representación mental das entidades deste nivel máis abstracto sitúanos xa fóra da memoria declarativa (que agrupa a memoria episódica e a semántica) en tanto que tales entidades non conteñen xa información referida á experiencia ou ao coñecemento do mundo. As construcións sintácticas son produto dun sistema de procedementos e estratexias deseñados para transmitir contidos declarativos (é dicir, son produto dunha gramática) e responden a un tipo de memoria a longo prazo executiva e automatizada que os psicólogos denominan, por oposición á declarativa, memoria procedemental.

No plano das construcións sintácticas, a diferenciación entre participantes centrais e periféricos tradúcese na distinción entre constituíntes que establecen relacións gramaticais centrais e non-centrais na predicación ou, o que en última instancia vén ser o mesmo, os que desempeñan funcións sintácticas (como $\mathrm{SU}$ ou $\mathrm{OD}$ ) e os que desempeñan funcións semánticas (como as tradicionalmente identificadas baixo a etiqueta de Complementos Circunstanciais). Cómpre unha rápida aclaración para non inducir a engano: é claro que todos os participantes dunha predicación, sexan actantes ou circunstantes, desempeñan unha función semántica (ou papel temático, ou rol gramatical), dado que todos xogan un determinado papel na representación do estado de cousas que se quere comunicar. Por contra, consonte se desprende do devandito, non todos desempeñan función sintáctica -igual que tamén non todos desempeñan función pragmática, cabería engadir.

Concibimos as chamadas funcións sintácticas como mecanismos gramaticais de identificación indirecta de funcións semánticas mediante marcas polivalentes ${ }^{2}$. Neste senso, as marcas en que consisten as 'funcións centrais', como o SU, serven para identificar, cunha mesma marca, múltiples roles semánticos distintos: un SU pode ser Axente, Forza, Experimentador, Posicionador, Meta etc., funcións todas elas que identificamos inequivocamente a pesar de estaren codificadas a través da mesma marca -a de SU: concordancia número-persoal no verbo. Pola súa banda, as marcas das 'funcións periféricas', por exemplo as de calquera CC, identifican directamente (é dicir, de maneira biunívoca, non polivalente) o rol semántico que desempeña o participante así marcado: un CC de Causa estará sempre identificado como tal a través dunha marca específica dese valor causal -por, a causa de, porque... Este tipo de marcas son directamente marcas de función semántica, e esta estratexia de marcado é característica dos participantes periféricos dunha predicación; as anteriores (as do tipo 'induce a concordancia verbal en número e persoa') son marcas de función sintáctica e alcanzan só aos participantes que desempeñan funcións centrais na predicación. Se ben o carácter non-universal (é dicir, non atribuíble inherentemente a todo o constituínte dun enunciado

2 En realidade, o tal carácter meramente instrumental destes mecanismos, localizados no plano da expresión e que non realizan ningunha contribución propia ao significado da oración en que aparecen, é incompatible coa súa consideración como funcións (vs. as semánticas e as pragmáticas, que si o son claramente). Con todo, por facilidade expositiva seguiremos denominándoos funcións sintácticas. 
polo feito de selo) é comunmente aceptado para o caso das funcións pragmáticas (na medida en que se consideren tales entidades, por suposto), o carácter non-universal das funcións sintácticas suscita menos adhesións, seguramente pola inercia de seren vistas como o vinculeiro que herda o legado indivisible da noción tradicional de función sintáctica, que si tiña ese carácter universal. Porén, non son poucos os modelos teóricos que sosteñen esta noción restritiva de función sintáctica, como a Gramática Relacional (que só identifica tres, R1, R2 e R3, correspondentes a SU, OD e OI) ou a Gramática Funcional de Dik (que só opera con dúas funcións sintácticas, Sux e Obx).

Mediante a asignación de funcións sintácticas -no sentido estrito en que aquí se aplica o termo- o falante codifica a maior prominencia conceptual que lle outorga a determinados constituíntes da predicación, como teñen posto de manifesto diferentes modelos teóricos funcionais e cognitivos. As marcas de expresión que identifican as funcións sintácticas son daquela correlativas desa prominencia; pero non semellan concibidas propiamente para marcala. Xa que logo, podemos categorizar discretamente as funcións e identificarmos a súa centralidade ou marxinalidade na configuración sintáctica da predicación, pero non podemos categorizar a prominencia dos participantes no evento, que só se marca dunha maneira indirecta e aproximativa. A prominencia dos participantes nunha predicación é unha noción intrinsecamente vaga, daquelas das que dicía Ferrater Mora (1976: 369) que "lo vago o borroso pueden ser inevitables y hasta deseables" dado que "el carácter vago o borroso del concepto es preferible a su carácter claro, ya que aquello que el concepto denota es tan vago y borroso como el concepto". A centralidade das funcións sintácticas é, por contra, unha noción escalar con categorías discretas (as propias funcións) que serve para evocar a prominencia dos participantes pero que ten existencia á marxe dela.

As características da oposición centro-periferia ata aquí expostas poden representarse sumariamente na seguinte táboa:

\begin{tabular}{|c|c|c|c|}
\hline $\begin{array}{c}\text { Nivel de } \\
\text { abstracción }\end{array}$ & $\begin{array}{c}\text { Representación } \\
\text { mental }\end{array}$ & $\begin{array}{c}\text { Plano } \\
\text { lingüístico }\end{array}$ & $\begin{array}{l}\text { Tipo de oposición } \\
\text { Centro vs. Periferia }\end{array}$ \\
\hline $\begin{array}{l}0 \text { concreto } \\
\text { individual }\end{array}$ & $\begin{array}{l}\text { memoria } \\
\text { episódica }\end{array}$ & $\begin{array}{l}\text { acto de } \\
\text { fala }\end{array}$ & + prominente $<\longrightarrow>-$ prominente \\
\hline $\begin{array}{l}1 \text { abstracto } \\
\text { substantivo }\end{array}$ & $\begin{array}{l}\text { memoria } \\
\text { semántica }\end{array}$ & léxico & actante / argumento vs. circunst / adxunto \\
\hline $\begin{array}{l}2 \text { abstracto } \\
\text { esquemático }\end{array}$ & $\begin{array}{l}\text { memoria } \\
\text { procedemental }\end{array}$ & sintaxe & 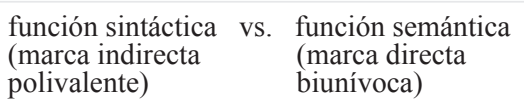 \\
\hline
\end{tabular}

Así pois, consonte teñen proposto diferentes modelos teóricos en forma de xerarquías, as relacións gramaticais poden caracterizarse escalarmente de acordo co seu grao de centralidade, sen esquecer que a relación existente entre a centralidade das funcións na configuración sintáctica da oración e a prominencia dos participantes na imaxe mental subxacente á predicación non é de identidade, senón de afinidade. 


\section{Funcións centrais e funcións non-centrais}

Sen dúbida o Suxeito (SU) é a función sintáctica caracterizada como máis central, en tanto que singulariza o "participante privilexiado" dunha construción (Moreno Cabrera 1991): asígnase ao único argumento nas construcións monoactanciais e nas poliactanciais ao único argumento que é ao mesmo tempo independente do evento denotado na predicación (a diferenza dos restantes argumentos, que codefinen ese evento) e responsable del, o que o sitúa nunha posición de privilexio no esquema argumental -como argumento externo vs. os restantes, internos. A esta situación de realce apuntan a caracterización do SU como "primary vantage point" en Dik (1997), como trajector, é dicir, "primary clausal figure” en Langacker (1991) ou como pivot en Foley e Van Valin (1984), entre moitos outros. Evidencia a súa condición de función sintáctica pivote non tanto a súa posición de prominencia conceptual como o feito (derivado dela) de que toda a configuración sintáctica do enunciado xira á volta do constituínte seleccionado como SU -por exemplo, a asignación das restantes funcións sintácticas é un subproduto da decisión de asignar SU a un argumento, non produto de decisións independentes dela.

A carón do SU, a outra función central por excelencia é o Obxecto Directo (OD), ás veces caracterizado simplemente como Obxecto. Ambos conforman o esquema oracional básico. Formulacións binarias como as de Dik (que identifica unicamente esas dúas funcións sintácticas: Sux e Obx) ou de Langacker (co binomio trajectorlandmark) apuntan a esta idea de centralidade compartida. Así se Sux é definido como "the primary vantage point", Obx serao como "a secondary vantage point" (Dik 1997: 249); se o trajector é a "primary clausal figure" o landmark será o "prominent element other than the trajector" (Langacker 1991: 350, 355).

SU e OD asígnanse sempre a entidades centrais e prominentes da predicación, pero a prominencia á que se asocian un e outro adoita ser sensiblemente distinta: a asignación de SU pon de manifesto a especial prominencia conceptual dunha entidade, é dicir a súa condición de figura particularmente relevante na configuración da imaxe mental subxacente; a función de OD, por contra, adoita estar correlacionada coa entidade dotada de maior prominencia comunicativa do enunciado, é dicir, aquela que lle imprime dinamismo á comunicación, favorecendo a apertura de novas imaxes mentais subseguintes da anterior ${ }^{3}$. Agora ben, se a asignación de SU pode

3 García-Miguel (1999) formula un principio xeral segundo o que os referentes máis prominentes na conceptualización tenden a codificarse na expresión lingüística coas formas menos 'pesadas' (as que empregan menos material fónico, mediante concordancia ou clíticos). Inversamente, cabe engadir que a prominencia comunicativa esixe un maior peso fónico: codifícase cun pico tonal e este só se pode aplicar en constituíntes lexicamente plenos. Segundo os datos achegados por García-Miguel (referidos ao español), o $75.40 \%$ dos OD das oracións transitivas teñen forma léxica, mentres que só a teñen o $21.90 \%$ dos seus SU, o que é indicio da alta prominencia conceptual e escasa prominencia comunicativa que caracteriza os SU, e á inversa no caso dos OD. 
considerarse como motivada en parte pola vontade de marcar gramaticalmente esa prominencia conceptual, a gramaticalización do OD como marca de prominencia comunicativa é moito menor, entre outros motivos porque, como se indicou máis arriba, a asignación de OD non é unha decisión libre, senón determinada pola escolla de SU. Así pois, o OD non gramaticaliza a prominencia comunicativa (marcada de seu a través da función pragmática Foco), aínda que adoita ser correlativo dela.

No outro extremo, as relacións gramaticais establecidas habitualmente polos circunstantes ou adxuntos, identificadas por etiquetas como CC ou OBL(icuos), constitúen o exemplo máis patente de funcións periféricas. Pero, consonte o dito anteriormente, neste caso non estamos xa de seu perante unha función sintáctica, senón diante dun agrupamento de funcións semánticas dificilmente caracterizables como unha función sintáctica (e menos como un feixe delas), pois as marcas de función destes complementos o que marcan, de maneira específica e biunívoca para cada caso, é o rol ou papel que cada un deles xoga na posta en escena que comporta toda predicación -é dicir, a súa función semántica. Por iso sempre se identifican e clasifican con criterios semánticos. Non obstante, con frecuencia quérese presentar estes complementos de circunstancia como unha función sintáctica, construída por acumulación de cousas distintas que non encaixan nas funcións sintácticas "ben definidas". Segue logo o consabido lamento do caixón de xastre e o imposible reto de o arrombar; mais a culpa non é do xastre, senón do propio deseño do caixón, o que torna as cousas ben máis complicadas.

O caso dos chamados Complementos Adverbiais (Rojo 1985, 1990) paréceme un exemplo ilustrativo do difícil que resulta a, na miña opinión, inviable tarefa de arrombar e definir as distintas relacións gramaticais supostamente ocultas baixo a desorde da etiqueta CC concibida como función sintáctica, proceso iniciado xa hai ben anos coa alarquiana distinción entre Aditamento e Suplemento. Os CAdv (residen en Vigo, portáronse con educación) son procesados pola lingua de xeito idéntico aos correspondentes CC (traballan en Vigo, faláronnos con educación), con independencia do carácter argumental de uns e non-argumental dos outros, que depende só do verbo da oración en que aparezan. Repárese na diferenza de planos lingüísticos en que nos movemos: o que contrapón os devanditos usos das frases en Vigo e con educación (a saber, a súa condición argumental vs. non-argumental) é lingüisticamente relevante, mais só no plano léxico; no plano sintáctico esa peculiaridade semella irrelevante, como demostra o feito de que careza de toda transcedencia formal (nin sequera indirecta, ata onde eu chego) nas construcións respectivas. Así pois, resulta improdutivo xebrar o CAdv como unha función 'sintáctica' diferente do CC.

Situados entre as funcións sintácticas $\mathrm{SU}$ e OD, representantes prototípicos de constituíntes centrais, e o conxunto de funcións semánticas habitualmente chamadas $\mathrm{CC}$ ou $\mathrm{OBL}$, de carácter claramente periférico, atópanse dous tipos de Complementos de Obxecto (non directo) particularmente interesantes no 
seu comportamento sintáctico, que responde ao seu particular estatuto na zona intermedia da escala de centralidade das funcións: trátase do Obxecto Indirecto (OI) e do Obxecto Preposicional (OP). Comecemos por poñer de manifesto todos os elementos que conforman esta rexión funcional intermedia dos complementos de Obxecto, para logo explorar as súas diferenzas e as diferrenzas conceptuais que uns e outros codifican.

Todos os constituíntes aos cales se lles asigna unha función de Obxecto (sexa OD, OI ou OP) teñen en común o feito de achegaren especificacións que axudan a precisar o tipo de evento referido polo verbo, cando a mera información léxica deste non se considera abonda. Intégranse pois todos eles na FV, realizando sucesivas operacións determinativas sobre o seu núcleo. Dependendo das características destas especificacións, diferéncianse os tres tipos de funcións sintácticas Obxecto, que o falante asigna consonte os distintos graos de prominencia cognitiva que en cada caso lle outorga aos constituíntes accesibles á función de Obxecto (que non son todos nin o son todos no mesmo grao):

1. Cando o verbo demanda unha complementación directa ou primaria da súa referencia, esta tenderá a adoptar a forma dun complemento OD, unido directamente ao verbo, sen mediar de seu preposición. Exs.: Canta nanas, Escribe unha carta.

2. En ocasións o verbo demanda, ou admite sen demandala, unha especificación adicional secundaria, que atinxe ao conxunto formado polo verbo e o seu adxacente primario, xeralmente un OD. Estamos daquela perante un complemento OI, introducido por unha (pseudo)preposición $a$ que, afastando o Obxecto do verbo, marca formalmente de maneira icónica ese carácter indirecto ou secundario da complementación. Exs.: Cántalle nanas ao neno, Escríbelle cartas ao mozo.

3a. Ás veces a especificación primaria que certos verbos demandan non é realizada de maneira directa por un OD, senón por un constituínte introducido por unha preposición (variable) que formalmente codifica un maior distanciamento semántico, unha menor implicación ou centralidade destes Obxectos non-directos (pero tampouco OI) que identificaremos co nome puramente descritivo de Obxecto Preposicional (OP). Exs.: Coida do neno, Tirou coas cartas.

3b. En ocasións o OP non realiza unha complementación primaria (é dicir, non ocupa o espazo funcional prototítpico dun OD) senón que achega unha especificación adicional secundaria, que atinxe ao conxunto formado polo verbo e o seu adxacente primario (un OD), polo que estamos perante un OP indirecto. Exs.: Limpou o camiño de silveiras, Concilia o traballo coa vida familiar, Separa o trigo do xoio. 
Poderíanse aducir numerosísimas evidencias de como o reparto na asignación das funcións sintácticas de Obxecto entre os constituíntes que especifican o tipo de evento designado nuclearmente polo verbo, responde en grande parte a unha cuestión de perspectiva conceptual, de relativa prominencia das entidades referidas por eses constituíntes na imaxe mental do falante. Referiremos unicamente dúas mostras:

(1) a. O camareiro serviulles uns cafés aos clientes da barra.

b. O camareiro serviulles aos clientes da barra uns cafés.

c. O camareiro serviu os clientes da barra. Serviunos axiña.

(2) a. Separa o trigo do xoio.

Concilia o traballo coa vida familiar.

b. Separa o xoio do trigo. Concilia a vida familiar co traballo.

c. Separa o trigo e o xoio. Concilia o traballo e a vida familiar.

En (1a), estrutura prototípica de dobre Obxecto (V-OD-OI), o OD codifica a maior prominencia relativa dos cafés na presentación do estado de cousas e na súa definición. En (1b) apréciase unha promoción da entidade os clientes da barra, que adquire un maior relevo na configuración da imaxe mental, de que é expoñente o seu avance na cadea lingüística, se ben non se reflicte nunha mudanza de función sintáctica (imposible en galego, fronte ao que ocorre noutras linguas, como o inglés, en que o constituínte promovido pasa a funcionar como Obxecto primario). Como amosa (1c), a omisión do OD removido acaba por habilitar o primitivo OI para que sexa tratado como un OD, en consonancia coa posición de prominencia conceptual de que goza.

A carón da secuencia de dobre complementación máis común (V-OD-OI), non son raras as secuencias V-OD-OP, especialmente frecuentes (aínda que non de xeito exclusivo) con verbos 'simétricos'. Como se aprecia nas estruturas de (2a-b), a asignación de cadansúa función Obxecto aos dous constituíntes involucrados reflicte unha opción de perspectiva, de prominencia relativa entre eles. Similarmente ás diferenzas entre o café con leite e o leite con café, o constituínte escollido como OD percíbese como a figura con máis peso específico na imaxe mental, mentres que a función OP codifica un menor relevo escénico do constituínte. De querermos presentar os dous constituíntes nunha perspectiva de igualdade, codificarémolos como un único OD, integrado por unha construción coordinativa $(=2 \mathrm{c})$.

\section{OI e OP: funcións converxentes, dinámicas contrapostas}

Fronte ao OD, función inequivocamente central que codifica unha situación (=non-dinámica) de prominencia intrínseca na escena mental, o OI e o OP son 
funcións menos centrais que conflúen na mesma rexión de centralidade intermedia respondendo, en boa medida, a estratexias dinámicas contrapostas: de promoción cara á zona central de constituíntes máis ou menos marxinais no caso dos OI e de desprazamento de elementos centrais cara á periferia no caso dos OP.

Queda dito que OD e OP realizan os dous unha complementación primaria do verbo, como dúas formas (canónica e atípica, respectivamente) da transitividade. Compárese (V-OD / V-OP):

(3) a. Coidar un neno / Coidar dun neno.

b. Tirar o vaso / Tirar co vaso.

c. Comer o pan / Comer no pan.

d. Lembrar algo / Lembrarse de algo.

e. Consultar un avogado / Consultar cun avogado. Etc.

Esta confluencia no mesmo espazo funcional levou a non poucos autores a veren en ambas as opcións dúas formas 'superficiais' unha mesma relación funcional básica (e.g. Cano Aguilar 1981: 365). Porén non hai tal identidade. Consonte o esperable, as diferenzas formais entre ambas as estruturas - tanto directas (presenza de preposición, clíticos) como indirectas (posibilidade de transformación pasiva) non son irrelevantes nin gratuítas, senón que codifican diferenzas funcionais. Como ben puxo de manifesto García-Miguel (1995b) para o español, mediante o esquema transitivo canónico S-V-OD o emisor sitúa os dous participantes no primeiro plano da escena, mentres que co esquema S-V-OP sitúa só o primeiro argumento nesa posición de prominencia. Por iso esta construción amosa, fronte á canónica, un perfil de transitividade moito máis baixo (do que é expoñente a imposibilidade de transformación pasiva, por exemplo), ata o punto de que se pode considerar un mecanismo de intransitivación sen redución argumental. Nunha clara mostra de iconicidade sintáctica, a presenza da preposición no OP, interpoñéndose entre $\mathrm{V}$ e $\mathrm{O}$, fai que a relación entre ambos deixe de ser directa, distanciándoos formal e semanticamente, e por tanto funcionalmente (Trujillo 1988: 199ss.; García Miguel 1995b: 95ss.). O OP xa non é a Meta en que culmina o evento, como o era o OD, senón un punto de referencia menos central, en que son máis ou menos perceptibles pegadas dos primitivos contidos concretos (basicamente locativos) das preposicións implicadas, por máis que se mudasen en relacións abstractas.

O OP é, pois, unha sorte de OD marxinalizado, unha especie de Obxecto indirecto que os falantes tratan, porén, como algo formalmente distinto dun OI. O feito de que OI e OP converxan na mesma zona central da transitividade, pero manténdose como mecanismos formalmente distintos non cabe supor que sexa unha circunstancia irrelevante: para marcar o desprazamento dun OD cara ás marxes, abondaba 
presentalo como un $\mathrm{OI}^{4}$. Consideremos daquela cal é o espazo que ocupa o OI neste cadro.

O OI é unha figura sintáctica moi complexa e polivalente e o seu estudo minimamente pormenorizado ultrapasa con moito os límites desta contribución ${ }^{5}$. Simplificando, daquela, as cousas podemos identificar de entrada dous grandes tipos de OI (exclúense os chamados 'dativos superfluos', realizados só mediante clíticos):

1) OI prototípicos, de carácter argumental: responden aos esquemas triactanciais, coa estrutura prototípica SU/Ax-OD/Met-OI/Rec. Non son moitos os predicados que proxectan estas construcións, mais si de bastante uso: case todos son verbos de transferencia, material ou comunicativa, dos tipos dar e dicir. Aínda sendo relativamente poucos, constitúen o núcleo sobre o que se forxa a descrición das propiedades prototípicas da función. Referirémolos convencionalmente como $\mathrm{OI}_{1}$.

2) OI promovidos: numericamente os máis frecuentes, do punto de vista semántico son moito máis heteroxéneos, pero responden a unha estratexia común de promoción dun constituínte non-argumental (ou eventualmente argumental pero prototipicamente periférico, véxase $4 \mathrm{~d}$ infra) ao que, asignándolle a función de OI, o falante lle outorga un rol central na posta en escena que a priori non tiña. Identificarémolos como $\mathrm{OI}_{2}$. Por exemplo:

(4) a. Comeu as galletas da nena $\rightarrow$ Comeulle as galletas á nena [Mod-OD $\rightarrow \mathrm{OI}]$

b. Mercou galletas para a nena $\rightarrow$ Mercoulle galletas á nena $[\mathrm{CC}-\mathrm{Ben} \rightarrow \mathrm{OI}]$

c. Esixo de Vde. unha escusa $\rightarrow$ Esíxolle a Vde. unha escusa $[\mathrm{CC}-\mathrm{Or} \rightarrow \mathrm{OI}]$

d. Colocou uns estores na ventá $\rightarrow$ Colocoulle uns estores á ventá $[\mathrm{CC}-\mathrm{Loc} \rightarrow \mathrm{OI}]$

Fronte aos OI prototípicos, que responden a unha posición estática e inherentemente central, a asignación de OI a estoutros constituíntes non-centrais responde a unha dinámica con que se procura outorgarlles maior prominencia conceptual da que tiñan como constituíntes OBL (ou como partes de constituíntes non-OBL, v. 4a). Esta dinámica é complementaria da que acabamos de ver no OP, cunha traxectoria oposta.

4 Cabería aducir os problemas de concorrencia con estruturas que xa tivesen un argumento coa función OI, pero non parece ser o caso, pois os OP non concorren con OI argumentais. É dicir, nas estruturas trivalentes S-V-OD-OI o OD non pode ser marxinalizado como OP (salvo no caso moi peculiar do OP partitivo con de: dálle iso a alguén $\rightarrow$ dálle diso a alguén); nestas estruturas o relego escénico parece marcarse na sintaxe só posicionalmente, mediante a posposición do OD ao OI.

5 Unha atinada visión de conxunto do OI (en español) podemos atopala en Vázquez Rozas (1995), monografía en moitos sentidos complementaria da de García-Miguel (1995b) sobre o OP. Ambas presentan puntos de vista afíns entre si e tamén en grande medida cos aquí expostos. 
Repárese en que agora o albo da promoción non é unha función nova, senón que se aproveita a máis próxima no chanzo superior da escala de centralidade (o $\mathrm{OI}_{1}$ ), o que debe está relacionado co feito, antes mencionado, de que o desprazamento cara á periferia oracional dos Obx non se realice a través de OI, senón dunha figura ad hoc como é OP. Aproveitar igualmente o OI levaría a un sobrecargo de valores e dificultaría o marcado do carácter menos-central-que-OI atribuído aos Obx desprazados ás marxes, que son tratados como algo máis próximo a un CC que a un OI.

Podemos, pois, representar a interacción entre as posicións funcionais estáticas e dinámicas no seguinte cadro (as casas grosas marcan as funcións centrais):

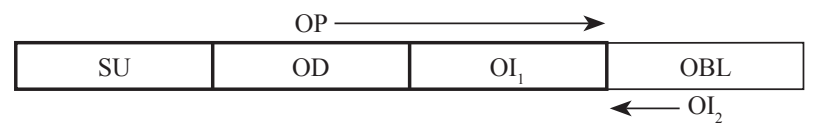

Este cadro condúcenos á seguinte escala de centralidade das funcións:

(5) $\quad \mathrm{SU}>\mathrm{OD}>\mathrm{OI}_{1}>\mathrm{OI}_{2}>\mathrm{OP}>\mathrm{OBL}$

As cousas son, abofé, máis complicadas e exceden os límites razoables desta contribución. Polas repercusións que ten na definición do grao de centralidade das funcións sintácticas referireime telegraficamente a unha peculiar estrutura sintáctica moi frecuente en algunhas linguas e insólita (ou mesmo imposible) noutras. Trátase dun terceiro grande tipo de OI que aparece en estruturas biactanciais, sen OD e cunha organización funcional e secuencial certamente singular (OI-V-SU), como as que ilustran os seguintes exemplos (á dereita, entre caixas, aparecen correlatos seus coa estrutura canónica SU-V-OD):

(6) a. A Bea gústanlle as novelas románticas [cfr. Bea ama as novelas románticas]

b. Ao neno non lle importan os cartos [cfr. O neno despreza os cartos]

c. Á mestra esgotáronselle os recursos [cfr. A mestra esgotou os recursos]

Dado que este OI ocupa habitualmente a posición temática característica do SU chamarémoslle OI subxectivo ou temático $\left(=\mathrm{OI}_{3}\right)$. Trátase dunha figura sintáctica estática (como $\mathrm{OI}_{1}$ ), no senso de que non é produto de ningunha caste de promoción escénica: os dous constituíntes implicados son de seu argumentais e centrais. Pero oponse a $\mathrm{OI}_{1}$ en tanto que é produto dunha asignación de funcións sintácticas (OI e SU) completamente atípica: na columna da dereita temos construcións afíns, mais coa estrutura sintáctica prototípica SU-V-OD. Estamos pois perante unha estrutura 
sintáctica marcada que é reflexo dunha configuración semántica anómala (Vázquez Rozas 1995), e que só é viable en linguas cunha concepción relativamente pouco temática do SU: ensáiense, por exemplo, as traducións inglesa ou portuguesa dos enunciados (6) para verificalo. Centrándonos no caso que nos ocupa, interesa salientar que nestas estruturas o SU é claramente un constituínte menos prominente que o OI: parece evidente que non cabe consideralo o 'vantage point' desde o que se constrúe o enunciado, a función pivote arredor da cal se artella a estrutura sintáctica da predicación, valores que asume de certo nestas construcións o OI. Isto obríganos a emendar a escala (5) cunha inclusión no cumio das figuras centrais, de xeito que quedaría como segue:

$$
\text { (7) }\left(\mathrm{OI}_{3}\right)>\mathrm{SU}>\mathrm{OD}>\mathrm{OI}_{1}>\mathrm{OI}_{2}>\mathrm{OP}>\mathrm{OBL}
$$

As parénteses marcan o carácter excepcional e restrinxido deste chanzo $\mathrm{OI}_{3}$ que só atopamos con certos predicados e mesmo neles sometido a unha forte tendencia á reanálise para convertelo ao esquema maioritario mediante a presentación do OI coas marcas de caso do SU: enunciados do tipo Bea gústalle as novelas, Eu non me importa son frecuentes en usos non 'coidados' da lingua. Mais trátase dunha reanálise truncada, pois non alcanza, como se ve, á marca clítica de OI, que permanece inalterada.

Sirva esta breve engádega postremeira para poñer de manifesto a notable ductilidade que amosa de seu a gradación da centralidade das funcións sintácticas: unha mesma función pode ocupar posicións sensiblemente distintas na escala e a través delas reflectir, de maneira parella, graos de centralidade moi diversos. Mais iso non supón quebra do valor das funcións sintácticas como pegadas da prominencia conceptual dos constituíntes. Esta mostra de maleabilidade do indicio é consubstancial ao carácter radicalmente lábil do indiciado.

\section{Referencias bibliográficas}

Atkinson, R. C. / Shiffrin, R. M. (1968): "Human memory: A proposed system and its control processes", en Spence, K. W. / Spence, T. (eds.), The Psychology of Learning and Motivation. Vol. 2 (New York: Academic Press).

Báez San José, V. (1988): Fundamentos críticos de la gramática de dependencias (Madrid: Síntesis).

Cano Aguilar, R. (1981): Estructuras sintácticas transitivas en el español actual (Madrid: Gredos).

Croft, W. / Cruse, D. A. (2004): Cognitive Linguistics (Cambridge: CUP).

Dik, S. C. (1997) [1989]: The Theory of Functional Grammar. Part 1: The Structure of the Clause (Berlin; New York: Mouton de Gruyter). 
Du Bois, J. W. (1985): “Competing motivations”, en Haiman, J. (ed.), Iconicity in Syntax: 343-365 (Amsterdam: John Benjamins).

Ferrater Mora, J. (1976): Diccionario de Filosofia (Madrid: Alianza).

Foley, W. / van Valin, R. D. (1984): Functional Syntax and Universal Grammar (Cambridge: CUP).

Givón, T. (1998): “The functional approach to grammar", en Tomasello, M. (ed.), The New Psychology of Language. Cognitive and Functional Approaches to Language Structure: 41-66 (Mahwah, N. J: Lawrence Erbaum Associates).

García-Miguel, J. M.(1995a): Las relaciones gramaticales entre predicado y participantes (Santiago de Compostela: Universidade de Santiago de Compostela).

García-Miguel, J. M. (1995b): Transitividad y complementación preposicional en español (Santiago de Compostela: Universidade de Santiago de Compostela).

García-Miguel, J. M. (1999): “La expresión de actantes centrales en español (romance) y bribri (chibcha): tipología, discurso y cognición”, en Vilela, M. / Silva F. (eds.), Actas do $1^{\circ}$ Encontro de Lingüística Cognitiva: 101-121 (Porto: Faculdade de Letras da Universidade do Porto).

Langacker, R. W. (1991): Foundations of Cognitive Grammar. Vol. 2: Descriptive Application (Stanford: University Press).

Moreno Cabrera, J. C. (1991): Curso universitario de lingüística general. Tomo I: Teoría de la gramática y sintaxis general (Madrid: Síntesis).

Moure, T. (1996): La alternativa no discreta en lingüistica. Una perspectiva histórica y metodológica (Santiago de Compostela: Universidade de Santiago de Compostela).

Rojo, G. (1985): “En torno a los complementos circunstanciales”, en Lecciones del I y II Curso de Lingüistica Funcional: 181-191 (Oviedo: Universidad de Oviedo).

Rojo, G. (1990): "Sobre los complementos adverbiales", en Jornadas de Filología / Profesor F. Marsá: 153-171 (Barcelona: Universitat de Barcelona).

TLP2 (1966) = Travaux Linguistiques de Prague, 2 [= Les problèmes du centre et de la périphérie du système de la langue] (Prague: Éditions de l'Académie Tchécoslovaque des Sciences).

Trujillo, R. (1988): Introdución a la semántica española (Madrid: Arco Libros).

Vachek, J. (1966): "On the integration of the peripheral elements into the system of language”, Travaux Linguistiques de Prague, 2: 23-37.

Vázquez Rozas, V.(1995): El complemento indirecto en español (Santiago de Compostela: Universidade de Santiago de Compostela).

Willems, D. (1981): Syntaxe, lexique et sémantique. Les constructions verbales (Gent: Rijksuniversiteit). 